This item was submitted to Loughborough's Institutional Repository by the author and is made available under the following Creative Commons Licence conditions.

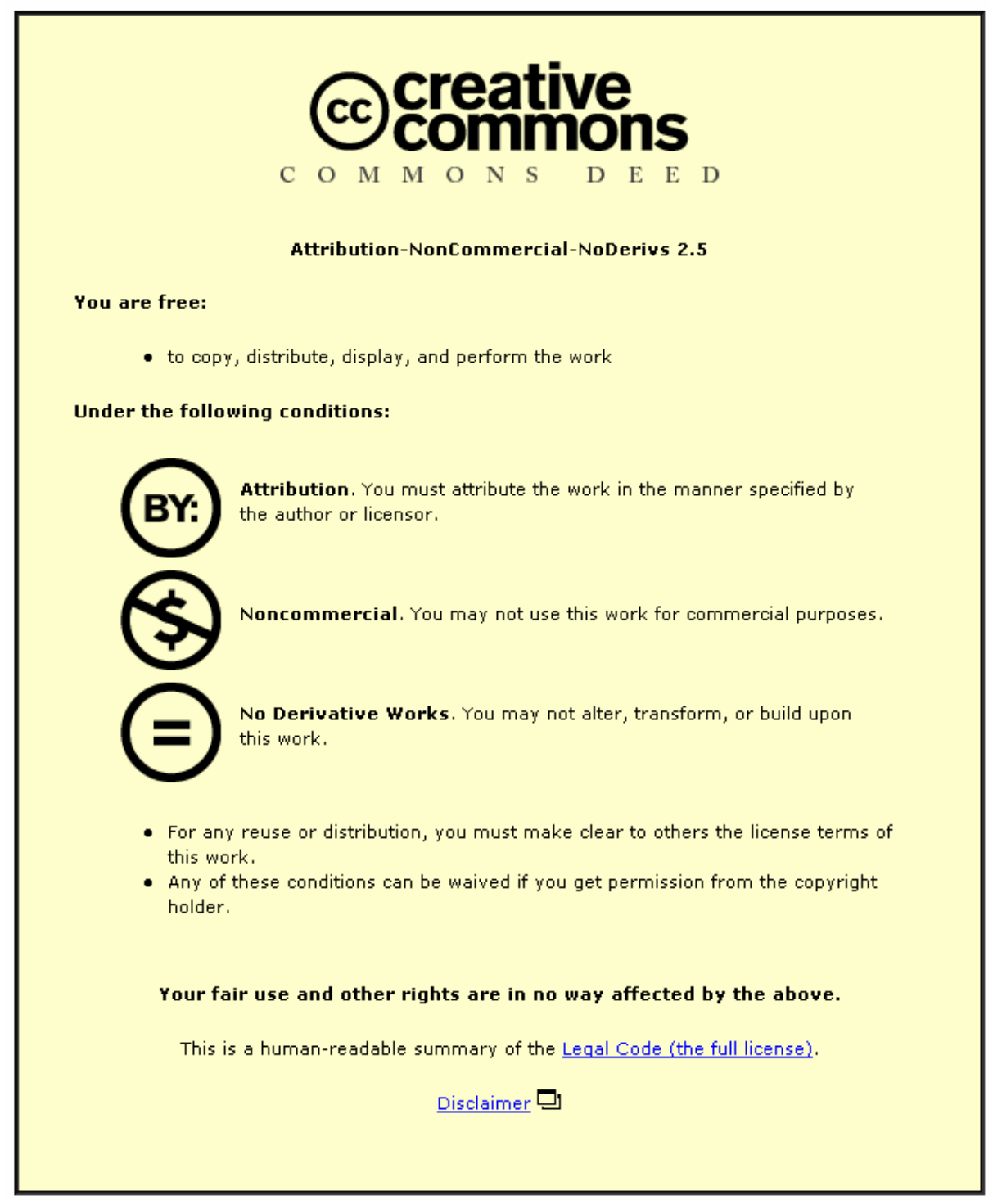

For the full text of this licence, please go to: http://creativecommons.org/licenses/by-nc-nd/2.5/ 


\title{
Threshold stress and asymptotic stiffness of UK clays in the repeated load triaxial test
}

\author{
M.W. Frost \\ The Nottingham Trent University, Nottingham, UK \\ P.R. Fleming \\ Loughborough University, Loughborough, UK. \\ C.D.F. Rogers \\ The University of Birmingham, Birmingham, UK.
}

Keywords: Stiffness, Permanent Deformation, Repeated Load Triaxial Test, Resilient Modulus, Performance Specification, Pavement Foundation Design.

ABSTRACT: Recent research at Loughborough University has produced a draft performance specification for pavement foundations. To assess the performance parameters of stiffness and resistance to permanent deformation of the subgrade, an extensive series of repeated load triaxial tests has been performed on a range of fine grained subgrades. Assessment of the data has shown that the deviator stress at which the cumulative permanent deformation starts to increase significantly (i.e. the threshold stress) is equal to half that at failure (and occurs at approximately 1\% permanent strain). The resilient stiffness of the materials tends to low asymptotic values at higher deviator stress. Comparison between the elastic and plastic behaviour has shown that the deviator stress at 'threshold' is coincident with the stiffness asymptote. This paper presents a suggested simplified mechanistic design approach for pavement foundations based on these findings.

\section{INTRODUCTION}

UK road pavements are traditionally designed in two stages, using a series of empirically designed road foundation layers (normally constructed of granular or stabilised materials) which provide a foundation upon which to construct a series of structural pavement layers.

The road foundation layers consist of capping (where necessary) and sub-base that overlie the natural soil subgrade. The capping layer is a subgrade improvement layer, and is regarded as a construction expedient to facilitate good compaction of the overlying layers. The capping is traditionally a low cost granular material that is ideally won locally or made by stabilising the subgrade with either lime or cement or both. Frequently it is an imported material. Sub-base is normally an imported, well-graded, good quality, granular material, and is regarded as a structural layer. It acts as a regulating course upon which to compact the bound layers.

The design is based on the current UK specification for road foundations (MCHW, 1994) which is a recipe approach, whereby selected materials are laid and compacted with specified plant in a specified manner to achieve a minimum assumed level of performance. The pavement foundation designs primarily use the California Bearing Ratio (CBR) to characterise the subgrade, capping and sub-base materials. The CBR is used as a measure of both material strength and stiffness. Although the use of CBR as a performance parameter is widely acknowledged as being not wholly satisfactory (Brown, 1996), CBR has been correlated with pavement performance over many years, in many countries, and has arguably provided a trusted empirical indicator of adequate material behaviour. Such an empirical approach based on CBR is unlikely, however, to result in the efficient use of materials and plant, does not easily allow for the use of recycled, new or marginal materials, 
and does not permit the use of rigorous analytical design procedures. In an attempt to move away from this empirical approach the UK Highways Agency has funded a programme of research (undertaken by Loughborough University in association with Scott Wilson Pavement Engineering Ltd) aimed at producing an appropriate performance-based specification for pavement foundations.

This paper presents some of the findings of this research with particular reference to laboratory testing of fine grained subgrades typical of those found in the UK. The paper describes the functional requirements of a pavement foundation and then details the requirements of a performance specification to assess these functions. It briefly explains the loading sustained and properties required of both (fine grained) subgrades and imported granular materials during their life in a pavement foundation, and then links this performance to properties that can be assessed for full analytical design. The results from an extensive series of repeated load triaxial tests to assess such design information are summarised and the key correlations observed presented. The potential of these correlations for use in a simplified analytical pavement design process is then suggested.

\section{A PERFORMANCE SPECIFICATION FOR PAVEMENT FOUNDATIONS}

For a pavement foundation to perform adequately the foundation must fulfil the following functions:

- It must support construction vehicles during the construction of overlying layers. The foundation must not deform sufficiently (i.e. undergo resilient deformation) under trafficking so as to reduce the effectiveness of the compacted structure. It must dissipate the applied stresses from the wheel loads to a sufficiently low level to ensure that the subgrade does not sustain significant permanent deformation (rutting).

- It must provide an adequate base for the placing and compaction of the overlying layers (i.e. it must not undergo large resilient deformations under the action of the compaction stresses such that it reduces the effectiveness of the compacted structure of the overlying layer(s)).

- It must provide adequate support to the overlying bound layers when the road pavement is inservice, and distribute the stresses transmitted through the bound layers to reduce the applied stress to the subgrade to a sufficiently low level. If it does not, flexural fatigue cracking of the upper layers can develop and propagate and the progressive accumulation of permanent strain (rutting) after a large number of small stress applications may lead to deterioration of the complete pavement.

In addition the materials used must possess chemical and physical stability in the long-term and the overlying materials must provide frost resistance to the subgrade.

To perform these functions the pavement foundations must possess the two primary performance parameters of adequate stiffness and resistance to permanent deformation, and any overlying materials must be sufficiently thick that their combined performance, as a composite structure ensures that the whole pavement structure performs adequately. To assess such performance within a performance based specification, the following four criteria must be satisfied:

- an ability to measure the performance parameters of the subgrade in the laboratory for both the short-term construction condition and the long-term in service condition,

- a method(s) of predicting accurately the environmental changes in the pavement,

- a means of incorporating the measured parameters in the design process,

- an ability to measure the same parameters on the subgrade and pavement layers in the field to assess compliance, and the setting of suitable target values for construction to provide assurance of the quality of the final product. 
Each of these elements presents a significant research challenge, and in particular this requires the assessment of both the stiffness and resistance to permanent deformation of the materials individually and as a composite for design, construction and the in-service condition.

\section{PERFORMANCE OF FINE GRAINED AND GRANULAR MATERIALS SUBJECT TO VEHICULAR LOADING}

\subsection{Pavement Loading}

To assess appropriate material properties for performance assessment, consideration of appropriate loading is required. When a pavement is subject to the passage of a vehicle wheel a stress pulse is generated, which consists of vertical and horizontal stress components with an approximately sinusoidal (double) pulse of shear stress (Brown, 1996). This stress pattern causes the element of the pavement to be subject to a rotation of its principal stresses (as opposed to a reversal in the shear stress caused by the application of a pulsed vertical load). Obviously this pulse varies with the speed, load and direction of the vehicle, and becomes repetitive with the passage of more wheels.

Generally the lower in a pavement, the lower the applied stress, due to the load spreading capabilities of the materials. Brown (1996) shows that a 165mm asphalt pavement (supported on $150 \mathrm{~mm}$ of granular material) subject to the passage of a laden wheel generates a subgrade stress of $15 \mathrm{kPa}$ with a pulse duration of approximately 0.6 seconds whereas a subgrade stress pulse beneath a $350 \mathrm{~mm}$ granular haul road is approximately $100 \mathrm{kPa}$, with a pulse duration of approximately 1 second.

\subsection{Performance of Pavement Materials Under Repeated Loading}

When pavement materials are subject to a cycle of load they sustain a deformation (i.e. a strain) which consists of two components (resilient and permanent deformation). The magnitude of each of these deformations defines the performance parameters of the materials. The resilient elastic stiffness is calculated from the resilient strain and the change in stress, measured on unloading. The permanent strain is found from the permanent change in dimension caused by the cumulative loading. There are many factors that affect the magnitude of each of these strains, and consequently material performance in a pavement. Some of these properties are summarised below.

\subsubsection{Fine Grained Materials}

The resilient stiffness of cohesive (fine grained) soils decreases non-linearly with increasing applied stress, when all other factors are kept constant (Seed et al, 1962). Materials exhibiting high suctions (negative pore water pressures) have been shown to have higher resilient modulus, indicating stiffness to be a function of three stress variables: the confining stress, the axial stress and the matric suction of the materials (Cheung, 1994). In addition soils tested at various repeated load frequencies $(0.1$ to $10 \mathrm{~Hz}$ and 0.05 to $0.5 \mathrm{~Hz}$ respectively) showed no significant changes in material performance with changing load frequency.

Permanent deformation has been shown to increase with the logarithm of the number of cycles, the rate of accumulation of permanent strain increasing as the stress increases. This eventually leads to a level where the rate of accumulation of deformation increases exponentially the stress at this point being defined as a threshold stress.

Cheung (1994) showed that the permanent deformation response of clay soils to repeated load depended primarily upon their stress history and water content, and thus shear strength. Therefore it has been suggested (Brown, 1996) that the dominant factor in determining permanent deformation is the relationship between shear stress applied (q) to the shear strength of the soil (i.e. stress ratio, $\left.\mathrm{q} / \mathrm{q}_{\max }\right)$.

A limiting value of $\mathrm{q} / \mathrm{q}_{\max }$ has been suggested ( $\mathrm{q}_{\text {threshold}}$ ), above which plastic deformation increases relatively rapidly. According to this relationship, the build-up of permanent strain should be 
approximately linear with the logarithm of the number of load applications for stress ratios that lie below the ratio for threshold stress (qthreshold). However, if q becomes greater than qthreshold, then the permanent strain increases at a markedly increased rate. Brown and Dawson (1992) suggest that for design purposes this threshold should be taken at a deviator stress equivalent to $50 \%$ of the soils' measured suction. Cheung (1994) proposed an alternative approach, suggesting that the threshold stress occurs at the deviator stress required to generate $1 \%$ permanent strain in a sample.

\subsubsection{Granular Materials}

Hicks and Monismith (1971) showed that the principal factor influencing the measured resilient properties of granular materials is the stress level. The stiffness (measured in a triaxial cell) was shown to increase significantly with increasing confining pressure and slightly with repeated deviator stress, as long as shear failure was not approached. The following simple relationship to predict material behaviour (known as the K- $\theta$ model) was proposed,

$$
\mathrm{M}_{\mathrm{r}}=\mathrm{K}_{1} \theta^{\mathrm{K}_{2}}
$$

where $K_{1}$ and $K_{2}$ are material parameters, and $\theta$ is the sum of the principal stresses $\left(\sigma_{1}+2 \sigma_{3}\right)$. This formula, although describing the general behaviour of granular materials, cannot be used to predict precise behaviour during loading and other more complex models have been proposed. However, the K- $\theta$ model is regarded as an adequate simplification for design purposes where other factors, such as adjacent material and layer parameters, affect response (Brown, 1996).

Permanent deformation induced in granular materials is shown to increase with increasing number of load cycles, and this has been found to be proportional to the logarithm of the applied number of cycles (Barksdale, 1972). Similar to fine grained materials, a limiting deviator stress below which permanent deformation remains stable has been identified: $70 \%$ of failure load has been suggested as a threshold stress (Boyce et al, 1976), and research is on going to define granular materials' shakedown limit.

\subsection{Composite Performance of Materials in a Pavements Foundation}

Much research has concentrated on defining the factors that affect the individual material behaviour. Yet the interaction between the imported foundation materials and the subgrade (composite behaviour) is also of crucial importance. The interaction between two layers of different (threshold) shear strength and elastic stiffness under transient loading produces a major influence on how each layer and type of material can act. If an unbound granular material overlying a softer, weaker subgrade is subject to loading, the deflections will be partially controlled by the upper layer as a result of its load spreading ability (stiffness). This controls the level of stress transmitted to the subgrade. However, the subgrade will influence the amount of load spreading that can take place by the way in which it reacts to the stress that is transmitted. Thus the layer interaction affects the stress distribution, which in turn affects the elastic and plastic strains that are developed (Fleming and Rogers, 1995).

The previous sections detail how the stiffness of pavement foundation materials varies with the degree of confinement and the applied stress. Therefore the properties within each layer of material within a pavement will vary with the magnitude of the applied stress, the layers relative position to that stress, the thickness of the layer, and that of the pavement structure as a whole, and the degree of confinement provided by the overburden from the pavement above.

If a large transient deformation is sustained under loading due to a poor subgrade, then the material in the upper layers will undergo significant bending. Due to the differences in the modular ratios of the different materials, there will be a difference in the reaction and movement of the materials above and below the boundary between layers. This differential response will in effect cause a change in the confining conditions at the interface in relation to the main body of the upper layer, and relative particle movement can occur. This reaction to loading provides the facility for significant plastic deformation to occur progressively with significant elastic deformation. At higher stress, beyond the threshold of the granular materials, the plastic strain within the pavement materials increases due to shearing. This in turn increases the applied stress to the subgrade and can lead 
to rutting. If a strong granular material is laid on a weak supporting layer the resultant composite deformation upon loading results in a particle reorientation due to low confinement. This leads to a rut forming in the granular material, hence increasing the applied stress to the subgrade. Therefore, the key to avoiding permanent deformation within the pavement materials is adequate shear strength, although if the applied stresses are still too great they can cause weakening and a progressive increase in the permanent deformation. However, a division between the stable and unstable build-up of material permanent deformation has been observed (Fleming and Rogers, 1995). Thus if the applied stresses in a pavement are maintained below the threshold values by providing adequate thickness of placed materials that have appropriate strength and stiffness, the formation and progression of rutting should remain within the stable zone.

\subsection{Laboratory Assessment of Material Performance}

From the above it is clear that the stiffness and permanent deformation characteristics are required for design. For fine grained materials, typical of those found in UK subgrades, sophisticated Repeated Load Triaxial Testing (RLTT) with on sample instrumentation has been developed to assess both stiffness and permanent deformation behaviour. However, due to the nature of the apparatus required, such testing has so far been limited to research laboratories. Whilst it is accepted that RLTT does not subject materials to a rotation of principal stress and thus underestimates permanent deformation, the assessment of threshold stress is possible and the RLTT has been suggested as the most appropriate apparatus currently available to assess parameters for design.

Assessment of the performance of granular materials can also be undertaken using RLTT, although there are significant research challenges concerning the assessment of granular materials with large particle size. However, dynamic plate testing may offer a way forward for the assessment of design parameters for such materials (Fleming et al, 2001).

\section{IMPLICATIONS FOR PERFORMANCE BASED FOUNDATION DESIGN}

From the above it can be seen that permanent deformation of the subgrade can be controlled by limiting the applied vertical stress, transmitted through the overlying layers, to a level below that causing a progressive increase in the accumulation of permanent deformation (i.e. below threshold stress). Such an approach forms the basis for the method of determining the design thickness of the unbound layers for UK railway track (Heath et al, 1972). Repeated load triaxial testing defined a limiting stress (i.e. $0.5 \mathrm{q}_{\max }$ ) related to observed field performance, which although a simplification provides practical guidance for design. It is clear from this discussion however that the current lack of routine sophisticated testing to assess the required performance parameters is restrictive to the development of analytical design using full performance assessment.

If the threshold can be derived by alternative means (as a proportion of $\mathrm{q}_{\max }$ or otherwise) only stiffness and stress dependency of the pavement materials needs to be measured for use in an analytical pavement design, based on limiting the transmitted subgrade stress. Such a design only needs to consider permanent deformation as a function of strength and material stiffness based on applied stresses through the composite, assuming the capping and sub-base have sufficient strength to avoid internal permanent deformations.

\section{REPEATED LOAD TRIAXIAL TESTING}

To assess the performance parameters defined above for a range of fine grained subgrade materials typical of those found in the UK, over sixty repeated load triaxial tests have been carried out. Samples were tested in a variety of states to model the conditions anticipated over the life of a pavement foundation (this is further discussed in Fleming et al, 1998):

- Undisturbed soil, as found in the base of cuttings at the time of construction, 
- remoulded, re-compacted soil at in situ water content, as found in embankments at the time of construction,

- samples in the two conditions above but at their equilibrium water content, which is often only achieved well after construction.

Other remoulded and wetted control samples were used to assess the apparatus repeatability.

Manually driven $100 \mathrm{~mm}$ diameter (U100) samples have been taken from various trial sites and live sites where other fieldwork has been undertaken. The RLTT equipment used was developed to form a prototype for a possible commercial test apparatus (Cheung, 1994). It requires samples of $100 \mathrm{~mm}$ diameter and $200 \mathrm{~mm}$ long. The samples are fitted with two on-sample strain measurement loops which measure the vertical strain over the middle third of the sample in order to remove end restraint effects caused by the load platens. The resilient strain is reported as the average of the readings from the on-sample gauges. A linear variable differential transformer (LVDT) is fitted to the top load platen to measure total sample strain. The sample is tested with an applied cell pressure of $20 \mathrm{kPa}$ to simulate the confining stress beneath a typical road pavement structure and subjected to an axial seating stress of $5 \mathrm{kPa}$. The samples are loaded for a set of 1000 cycles of deviator stress that is increased in $10 \mathrm{kPa}$ increments applied at a frequency of $2 \mathrm{~Hz}$. At $5 \%$ cumulative permanent strain the cyclic loading is stopped and the sample is loaded monotonically to failure. The resilient modulus is calculated from the 999th cycle of each load increment, with the final 10 cycles of each increment being investigated to ensure that the 999th cycle is representative.

Undisturbed samples were prepared directly from the U100 samples and tested. Remoulded samples were prepared from soil broken up in a mixer (until it formed lumps of less than $5 \mathrm{~mm}$ ), and compacted in a $100 \mathrm{~mm}$ diameter, $250 \mathrm{~mm}$ high Procter compaction mould in five equal layers using a $2.5 \mathrm{~kg}$ hammer falling through $300 \mathrm{~mm}, 27$ blows being applied to each layer.

\section{REPEATED LOAD TRIAXIAL DATA}

Figures 1 and 2 show typical resilient (stiffness) and permanent strain data for a number of samples and are typical of those for all materials assessed. Comparable permanent and resilient stain data are plotted with similar pattern lines on each figure. As expected the samples follow the typical trends expected of cohesive subgrades. The stiffness (resilient strain data) presented in Figure 1 shows inverse stress dependency in that the higher the value of cycled deviator stress the lower the stiffness. At higher stresses the stiffness reduces to approximately constant value, where minimal change in stiffness is seen with a large increase in applied stress. This value is considered to be a stiffness asymptote.

The permanent strain behaviour of the samples, Figure 2, shows direct stress dependency in that the lower the applied stress the lower the permanent strain. Initially the permanent strain increases nominally, but as the deviator stress rises the permanent strain increases exponentially beyond a point considered to be the threshold.

Similar patterns of resilient and permanent strain behaviour were seen for all samples, although the stresses at which the stiffness asymptote and threshold stress were reached were different for each sample. Similar materials at similar water content were shown to have similar asymptotes and threshold stresses despite their behaviour at lower stress being significantly different (Figure 1 and 2). Considerable variability in data recorded from samples taken from small areas of the same sites was observed, particularly at lower applied stress, and this is a potential concern if such strain data is used for design. However at higher stresses this variability is reduced. 


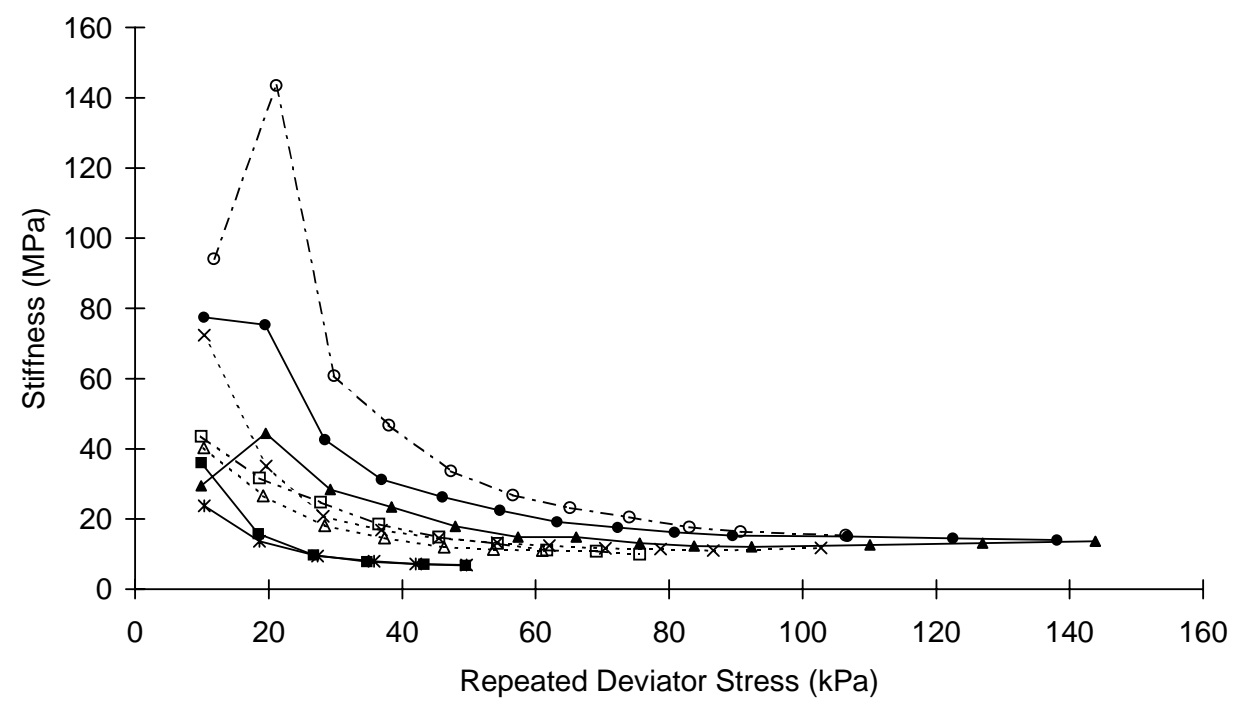

Figure 1. Typical relationships between deviator stress and stiffness

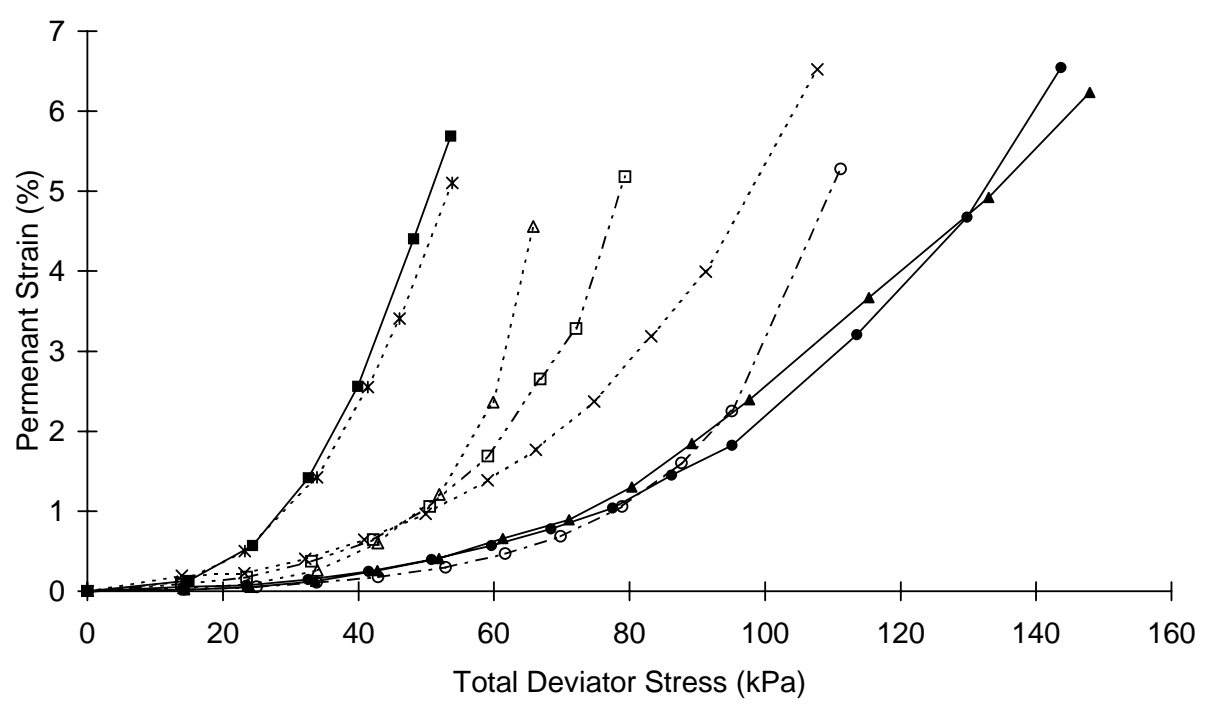

Figure 2. Typical relationships between deviator stress and permanent strain

The strain performance of the samples at higher strain was investigated in an attempt to define the point at which the threshold stress was reached. Two approaches have been used to assess threshold stress relative to sample strain, namely defining the threshold as the stress at which $1 \%$ sample permanent strain is reached (Cheung, 1994) and defining the threshold at the point of maximum curvature assessed from plots of stress Vs permanent strain. Threshold stresses defined in these two ways are plotted against the samples' undrained shear strength in Figure 3. The data from the two methods are shown to be comparable the lines of best fit show the two approaches to give broadly similar lines of correlation.

Figure 3 also shows two lines plotted using a suggested stress approach using shear strength to define threshold. The first represents threshold $=0.5 \mathrm{q}_{\max }$ i.e. one half the deviator stress at failure, which is equal to the undrained shear strength $(\mathrm{Cu})$ of the sample. This is a similar approach to that 
suggested for railways, and to the suction approach suggested by Brown and Dawson, (1992), and gives a line similar to the correlation lines for the two strain approaches. The second line shown on Figure 3 is a suggested conservative design threshold approach at $0.25 q_{\max }$ (i.e. threshold $=0.5 \mathrm{Cu}$ ). This line lies below the majority of the data points and should therefore give confidence that if applied subgrade stress is maintained below this level then permanent deformation should be well within the stable zone.

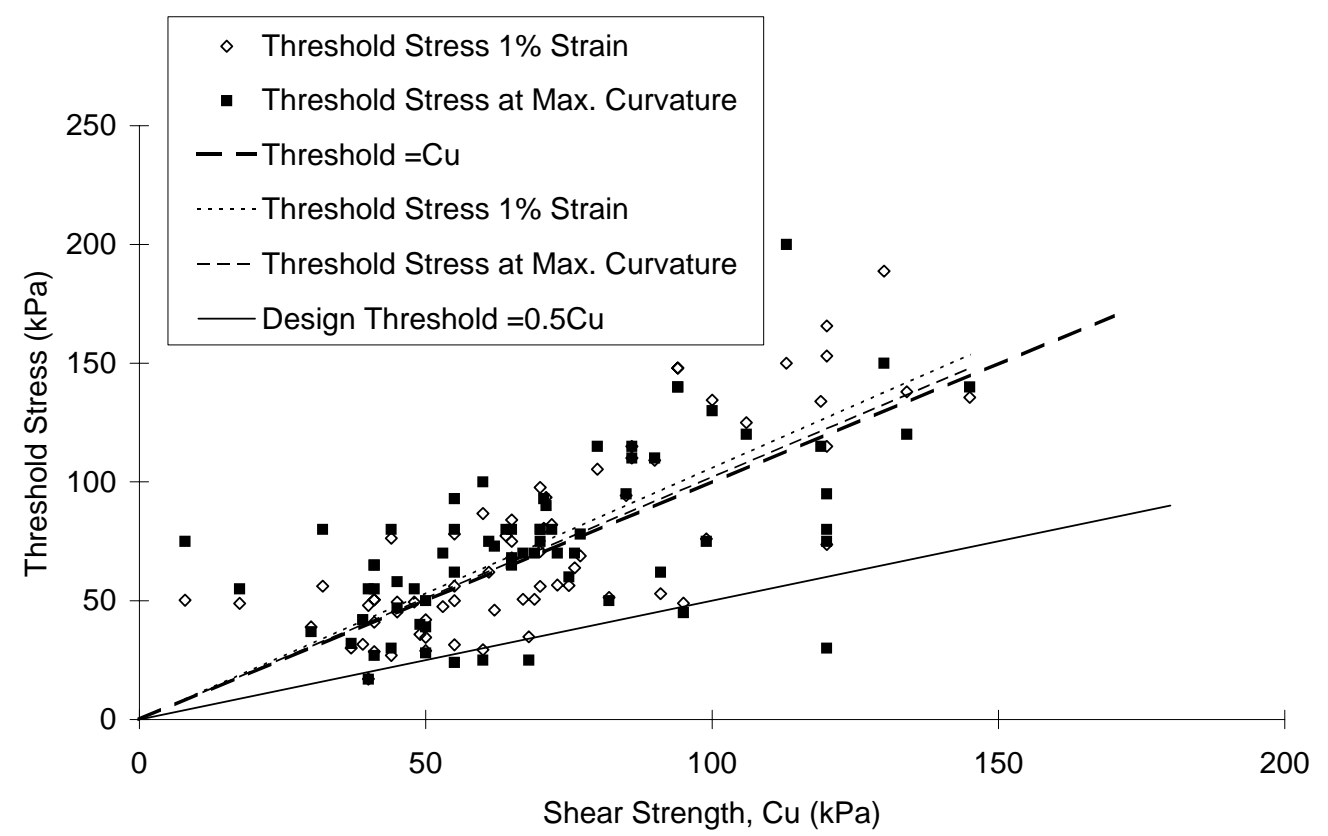

Figure 3. Relationship between un-drained shear strength and threshold stress

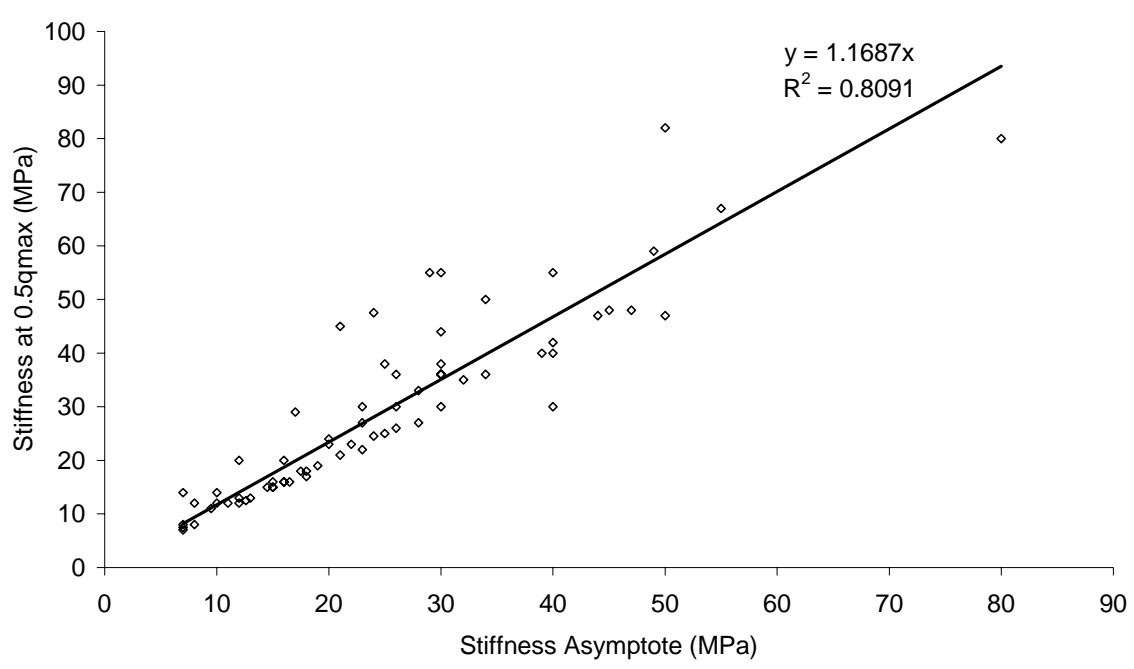

Figure 4. Relationship between stiffness asymptote and stiffness at threshold stress

Figure 4 shows the values of stiffness at a deviator stress of $0.5 q_{\max }$. These stiffnesses are compared to the asymptotic stiffness values assessed from the data, and show a linear relationship with 
a good correlation. This suggests that when a sample has reached the threshold stress (the development of permanent sample strain is becoming unstable), the stiffness is at or approaching a constant value (therefore resilient strain becomes directly proportional to applied stress), hence giving a stiffness asymptote.

\section{IMPLICATIONS FOR DESIGN}

The threshold relationships defined above are of potential use in design. If the strength of subgrade samples can be accurately measured, this can be related to a limiting allowable applied subgrade stress via the threshold shear strength relationship defined. This limit can then be applied in design for the worst case construction condition i.e. to design the foundation for construction trafficking. It is suggested that stiffness values (and subgrade stress dependency) could possibly be assessed simply within a standard triaxial cell with monotonic loading and unloading, as stiffness is not significantly load rate or stress history dependent. Alternatively, a single value of stiffness measured at threshold stress (the asymptote) should be appropriate for short-term construction design. These subgrade data could be coupled with stress dependency of the overlying granular materials, potentially measured via dynamic plate tests or determined using standard relationships derived from a $\mathrm{K} \theta$ model. Simple analysis to derive foundation thickness can then be performed using iterative elastic analysis.

For the longer-term service condition it is anticipated that the subgrade will have reduced in strength due to equilibration of pore water pressures (dissipation of suctions). However in service the applied subgrade stress is lower, thus subgrade stiffness higher, and the use of a short-term (lower) asymptotic stiffness should therefore still be conservative for design compared to a stiffness at low stress for a similar but wetter material (Fleming et al, 1998).

Limited back-analysis of field trial rutting data on trials constructed with standard granular materials (Frost, 2000) has indicated that the magnitude of the rutting observed was ranked according to the magnitude of applied subgrade stress. Where applied stress was below $0.5 \mathrm{q}_{\max }$ limited rutting was observed. Back-analysed designs for these same data using the above method and field derived granular material stress dependency gave comparable foundation thickness to conventional CBR based designs.

\section{CONCLUSIONS}

The maximum stress experienced by a subgrade, excepting perhaps that due to compaction of the materials itself (which does not cause damage) occurs during construction trafficking and this is the worst case for design. Therefore design to limit permanent deformation during construction is the primary design case. Long-term service conditions will not be so onerous, even though the performance of the subgrade will often be adversely affected by the loss of suctions as the equilibrium water content is established, as subgrade stresses will be far lower.

To control permanent deformation within a pavement the materials used must have sufficient strength and have adequate stiffness. These two properties combine to give a composite foundation within a complete pavement that can dissipate applied stresses to a sufficiently low level such that excessive permanent and transient deformations will not occur.

A value of applied cyclic deviator stress above which the onset of permanent deformation becomes unstable is shown to occur at approximately deviator stress at failure $\left(0.5 \mathrm{q}_{\max }\right)$. The stiffness at a deviator stress of $0.5 \mathrm{q}_{\max }$ is shown to be approaching a minimum (i.e. a stiffness asymptote). This suggests that for fine grained materials where permanent strain is becoming unstable, stiffness is tending to a constant value.

A simplified design approach is suggested whereby subgrade stress is limited based on threshold stress, which is assessed from a correlation with shear strength. Preliminary designs with this method have given values comparable to conventional design. 


\section{ACKNOWLEDGEMENTS}

The authors are grateful to Scott Wilson (PE) Ltd. and Nottingham University for their collaboration on this work, and to the UK Highways Agency for funding the research. The opinions expressed are those of the authors not the UK Highways Agency.

\section{REFERENCES}

Barksdale, R.D. 1972. Laboratory Evaluation of Rutting in Base Course Materials. Proceedings, 3rd International Conference on Asphalt Pavements. University of Michigan, Ann Arbor, USA, pp. 161-174.

Boyce, J.R., Brown, S.F. and Pell, P.S. 1976. The Resilient Behaviour of a Granular Material Under Repeated Loading. Proceedings of the Australian Road Research Board (ARRB). Vol. 8, Sydney, Australia, pp. 8-19.

Brown, S.F. 1996. Soil Mechanics in Pavement Engineering. 36th Rankine Lecture of the British Geotechnical Society. Geotechnique, Vol.46, No.3, pp. 383-426.

Brown, S.F. and Dawson, A.R. 1992. Two Stage Mechanistic Approach to Asphalt Pavement Design. Proceedings of the 7th International Conference on Asphalt Pavements, Vol. 1. International Society for Asphalt Pavements, University of Nottingham, Nottingham, UK, pp. 16-34.

Cheung, L.W. 1994. Laboratory Assessment of Pavement Foundation Materials. Ph.D. Thesis, University of Nottingham, Nottingham, UK.

Fleming, P.R. and Rogers, C.D.F. 1995. Assessment of Pavement Foundations During Construction. Transportation, Proceedings of the Institution of Civil Engineers, Vol. 111, No. 2, pp. 105-115.

Fleming, P.R., Rogers, C.D.F., Dawson, A.R. and Frost, M.W. 1998. Subgrade Equilibrium Water Content and Resilient Modulus for UK Clays. Proceedings of the International Symposium on Subdrainage in Road Pavements and Subgrades. World Road Association, Granada, Spain, pp. 359-366.

Fleming, P.R, Frost, M.W. and Rogers, C.D.F. 2001. Assessment of a Performance Specification Approach to Pavement Foundations. Transport Research Record. TRB Washington TRR (in press)

Frost, M.W. 2000. The performance of Pavement Foundations During Construction. Ph.D. Thesis, Loughborough University , UK.

Heath, D.L, Shenton.M.J., Sparrow, R.W. and Waters, J.M. 1972. Design of Conventional Rail Track Foundations. Proceedings of the Institution of Civil Engineers. Vol 51. pp 251-267

Hicks, R.G. and Monismith, C.L. 1971. Factors Influencing the Resilient Response of Granular Materials. Highways Research Report 345. Highways Research Board, pp. 15-31.

MCHW 1994. Specification for Highway Works. Manual of Contract Documents for Highway Works, Vol. 1. HMSO, London, UK.

Seed, H.B., Chan, C.K., and Lee, C.E. 1962. Resilience Characteristics of Subgrade Soils and Their Relation to Fatigue Failures in Asphalt Pavements. Proceedings of the International Conference on the Structural Design of Asphalt Pavements. University of Michgan, Ann Arbor, USA, pp. 611-636. 